\title{
SOME PALAEOMAGNETIC MEASUREMENTS IN ANTARCTICA
}

\author{
G. Turnbull*
}

\section{Introduction}

$\mathbf{T}$ HE mean direction of magnetization of rock formations of a particular age may be taken to represent the mean geomagnetic field at the time they were formed (Creer et al. 1957). There are strong theoretical reasons for believing that the mean geomagnetic field, obtained by averaging over many thousands of years, closely approximates to that of a geocentric dipole along the axis of rotation (Runcorn 1954). Thus the sampling of a series of sediments of more than a few feet in thickness, or a succession of lava flows, enables the ancient position of the rocks relative to the axis of rotation of the earth to be determined.

In recent years palaeomagnetic methods have provided information from most of the major land masses of the earth on the respective orientations of the geomagnetic field - from which may be deduced the position of the pole with respect to those land masses - during the geological past. It seems probable, if the above premises are correct, that both polar wandering and continental drift have occurred, the latter more particularly between southern continents.

The activity engendered by the International Geophysical Year 1957-8 provided an opportunity to obtain suitable rock specimens from the antarctic continent, and the author was able to visit two localities in Victoria Land. At Cape Hallett $\left(72^{\circ} \mathrm{S} ., 1^{\circ} \mathrm{E}\right.$.) the prominent Cenozoic volcanics were sampled, but the Palaeozoic sediments of the Robertson Bay group, quite highly metamorphosed in this region, were rejected as unlikely to provide reliable data on the ancient magnetic field. In the Ferrar Glacier region $\left(78^{\circ} \mathrm{S} .1^{\circ} 161^{\circ} \mathrm{E}\right.$.), samples were collected from the late Palaeozoic/ early Mesozoic Beacon sandstone, and from the extensive Mesozoic dolerite sills intrusive within the sandstone series.

The remanent magnetizations of the rocks collected were measured at King's College, University of Durham. A sensitive astatic magnetometer was employed to measure the weaker magnetization of the sedimentary rocks and a simpler instrument was used for the more strongly magnetized igneous specimens (Collinson et al. 1957).

Mean directions of magnetization and corresponding pole positions were calculated, and the 95 per cent level of confidence estimated in the usual way (Fisher 1953, Creer et al. 1957).

\footnotetext{
* Physics Department, King's College, Durham University, Newcastle upon Tyne.
} 


\section{Acknowledgements}

The project was instigated and largely arranged by Prof. S. K. Runcorn of the University of Durham, Physics Department, King's College, Newcastle upon Tyne. The work was made possible through the courtesy of the United States National Committee for the IGY, on behalf of whom the Arctic Institute of North America engaged the author to collect palaeomagnetic samples in Antaretica. Financial support for the laboratory work in King's College was provided by the Department of Scientific and Industrial Research.

\section{Results}

\section{Cenozoic volcanics of Cape Hallett $\left(72^{\circ} \mathrm{S} ., 171^{\circ} \mathrm{E}\right.$.)}

Twenty-three oriented samples were taken from the Cenozoic lava flows occurring in the neighbourhood of the United States/New Zealand IGY station at Cape Hallett. Twenty-one of these were magnetized in the reverse sense, that is, with a magnetization essentially antiparallel to the present geomagnetic field (Table 1, Fig. 1). This in itself suggests that the magnetization is stable.

The oval of confidence about the ancient pole position just fails to include the present geographic pole. It is probable that some error would

Table 1. Results of measurements.

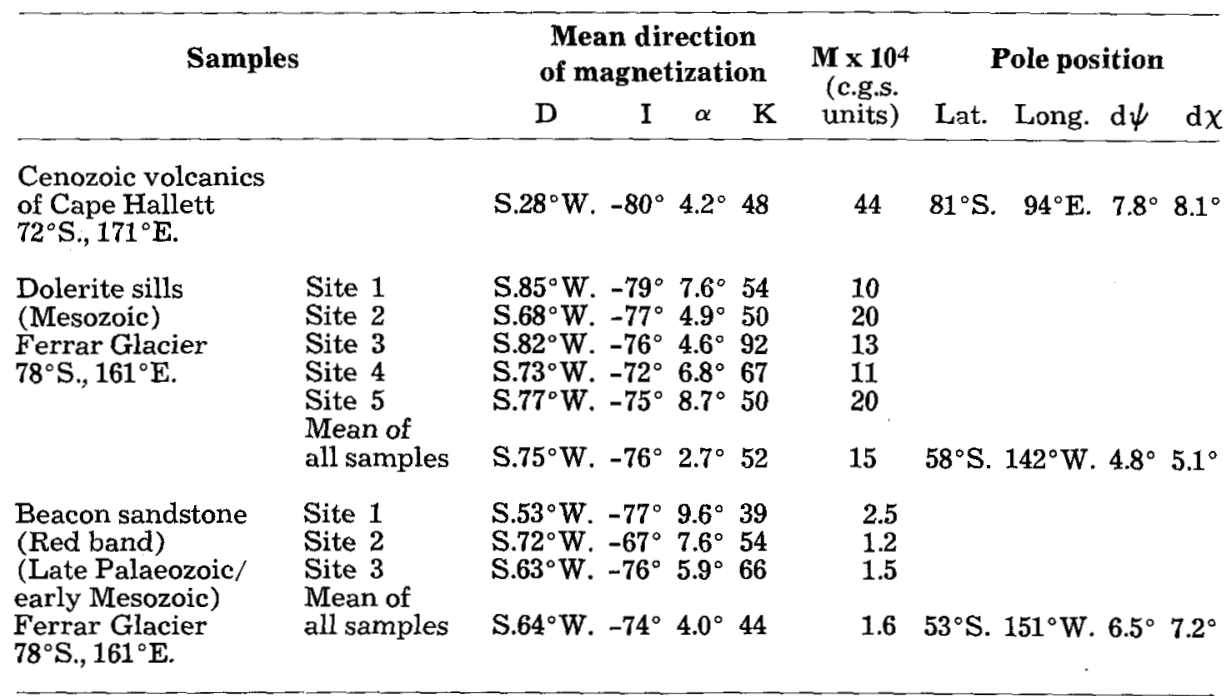

$\mathrm{D}$ - declination of the magnetization vector

I - inclination of the magnetization vector (positive below the horizontal plane)

$\alpha$ - semi-angle of the 95-per-cent cone of confidence

$\mathrm{K}$ - precision (Fisher 1953)

$\mathrm{M}$ - logarithmic mean intensity of magnetization (magnetic moment per unit volume)

$\psi, \chi$ - semi-axes of the oval of confidence about the pole position at the 95-percent probability level (Creer et al. 1957) 


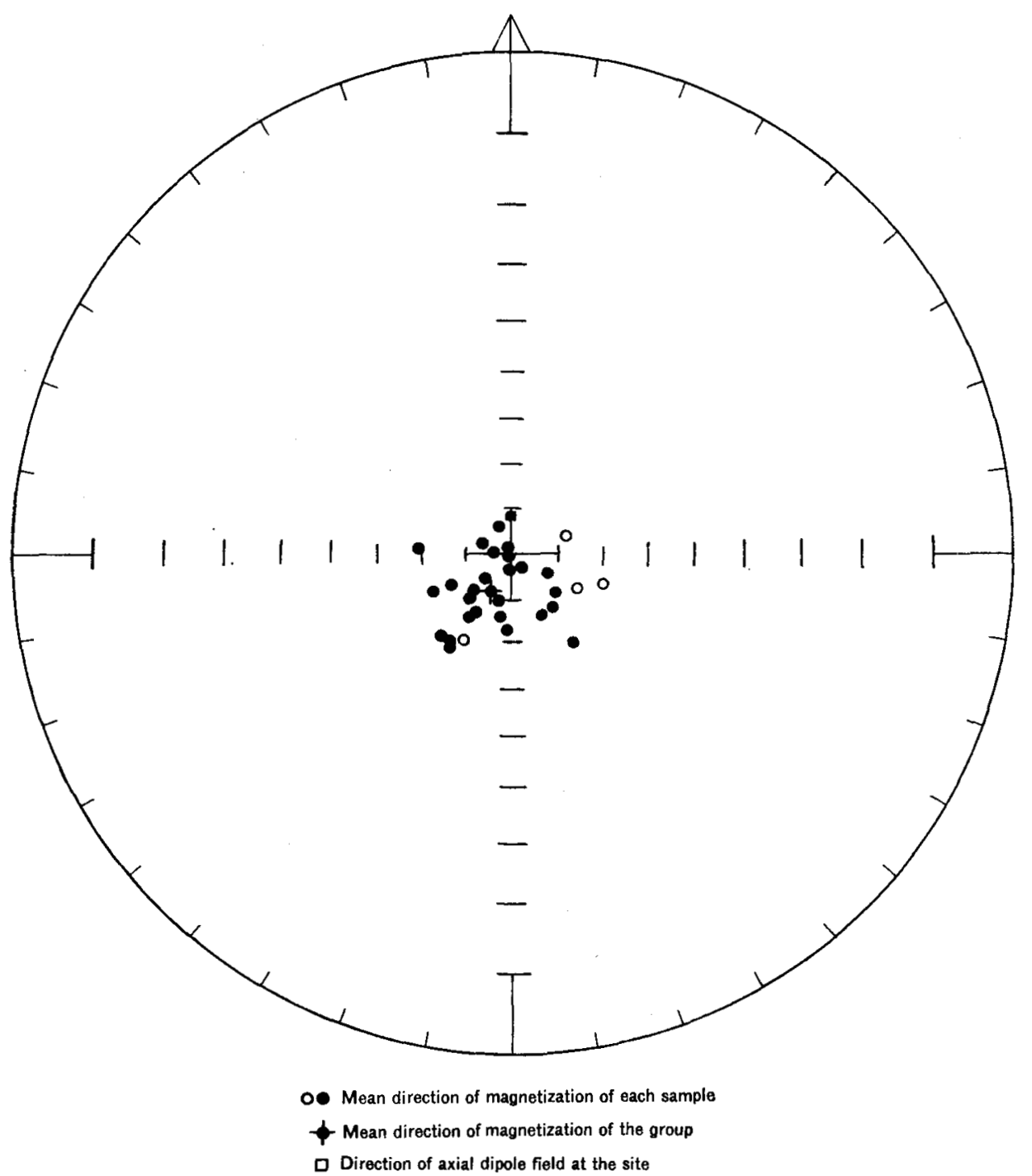

Fig. 1. Cenozoic volcanics of Cape Hallett - Direction of magnetization. The polar stereographic projection is used. Full symbols represent directions inclined downward ( + ve), open symbols directions inclined upward, projected respectively on the lower and upper hemisphere.

be introduced by imperfect averaging of the secular variation, and since the field relations were insufficiently clear to rule out entirely the possiblity of post-formational movements, this difference must be considered as of doubtful significance. The result agrees with earlier palaeomagnetic evidence, which shows that in both hemispheres the average geomagnetic poles have been aligned along the present axis of rotation for the last 20 million years (Hospers 1955, Irving and Green 1957). 


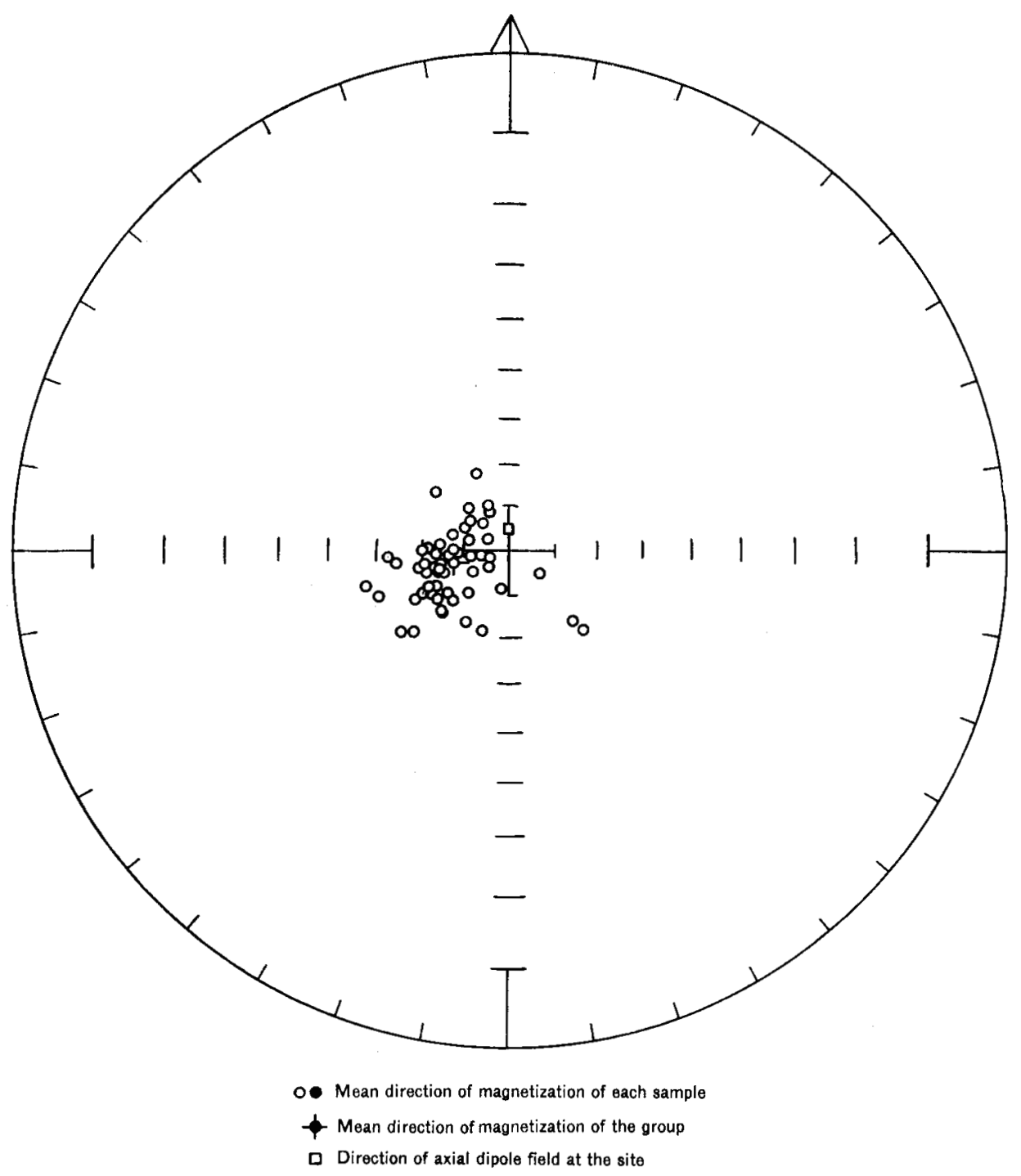

Fig. 2. Dolerite sills of Victoria Land - Direction of magnetization.

The two remaining samples were normally magnetized, with the same polarity as the present field of the earth, but in both instances field relations were suggestive of non-contemporaneity with the larger group. To make sure that the "normal" magnetization was due to a stable thermo-remanent magnetization, rather than to a soft isothermal component of magnetization associated with the present field, the two specimens were subjected to demagnetization in an alternating field of 500 gauss (Creer 1958).

A reduction in intensity of magnetization to 20 to 30 per cent of the initial value was effected, but the shortened magnetization vector maintained the same polarity and essentially the same orientation. 


\section{Dolerite sills of Victoria Land (Ferrar Glacier, $78^{\circ} \mathrm{S} ., 1^{\circ} \mathrm{E}$.)}

The uniformly horizontal sandstone typical of Victoria Land is intruded by dykes and vast sills of dolerite, believed to be of Jurassic or early Cretaceous age. Individual sills are usually some hundreds of feet thick, the aggregate thickness being over 4,000 feet (Debenham 1921).

Fifty-seven samples were collected from five sites near the upper Ferrar Glacier. Good exposures were found in dry valleys, cut during a period of more intensive glaciation and contingent upon the main glacier. Sites 2, 3, and 4 fell within a radius of about 5 miles, sites 1 and 5 were about 10 miles on either side of this central position.

All specimens were magnetized normally, with a mean direction rather close to the present field. (Table 1, Fig. 2). Whereas the comparatively high values of the precision $K$ (Fisher 1953) suggest a significant result, it is not immediately apparent whether a less stable "soft" component of magnetization aligned in the not wholly dissimilar direction of the geocentric dipole field is present. Stability tests dependent upon field relations as described by Graham (1949) were precluded by the uniformly horizontal nature of the strata. As a laboratory test a selected number of specimens were subjected to demagnetization in an alternating field of 500 gauss. A change in mean direction of magnetization of less than 3 degrees of arc was effected but the mean intensity of magnetization was reduced to 40 per cent of its initial value. It may be inferred that any isothermal component present is negligible in comparison with the thermo-remnant magnetization, so that the result obtained is representative of the ancient field.

A single dolerite specimen from the Queen Maud Range, at $83^{\circ} \mathrm{S}$., $30^{\circ} \mathrm{W}$., some 1200 miles distant from the Ferrar Glacier site, was reversely magnetized, with a direction

$$
\mathrm{D}=\mathrm{S} .31^{\circ} \mathrm{W} ., \quad \mathrm{I}=+67^{\circ}
$$

On the basis of a magnetic pole at $58^{\circ} \mathrm{S}$., $141^{\circ} \mathrm{W}$., the expected direction of reversed magnetization at this site would be $\mathrm{S} .60^{\circ} \mathrm{W}$., $+71^{\circ}$, some 12 degrees of arc from the experimental result. The probability that a single direction differs from the mean by an angle of more than $\psi$ is given by the formula

Prob. $(\psi>\psi \mathrm{o})=$ Exp. $-\mathrm{K}(1-\cos \psi) \quad$ (Watson and Irving 1957)

If the value of the precision observed on the Ferrar Glacier collection $(\mathrm{K}=52)$ is typical, a probability of about 32 per cent is implied. It may be concluded that this isolated observation is not inconsistent with the postulated position of the ancient pole.

\section{Beacon sandstone series (Ferrar Glacier, $\left.78^{\circ} \mathrm{S} ., 1^{\circ}{ }^{\circ} \mathrm{E}.\right)$}

A thickness of some 5,000 feet of uniformly horizontal sediments, assigned to the period Devonian - Triassic, overlies the basal complex in the McMurdo Sound region (Debenham 1921). The typical facies is a pale sandstone or quartzite, conspicuously lacking in the iron compounds upon which palaeomagnetic investigations depend. A few samples of this type were collected, 
but in the main were too weakly magnetized for significant measurement. Exceptions were two quartzite specimens, baked by adjoining masses of dolerite. Their direction of magnetization agreed closely with that of the dolerites, as would be expected of a thermo-remanent magnetization acquired by reheating in the contemporary field.

A 40-foot thick band of an argillaceous sandstone, mottled red and green, and interlaced with narrow vertical bands of coarser pale sandstone, similar to the overlying strata and suggestive of root cavities, was found in the upper part of the sequence.

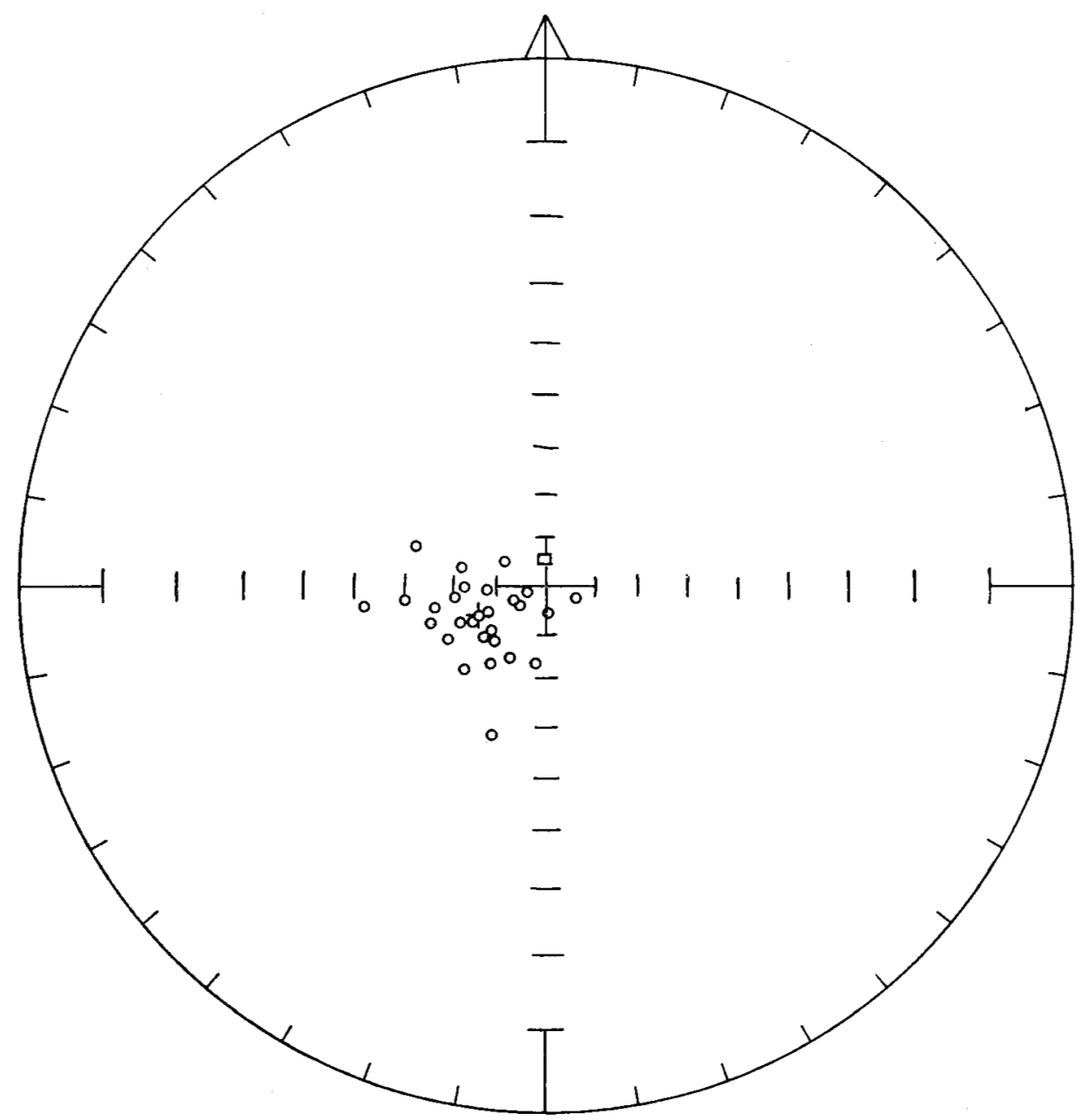

\footnotetext{
- Mean direction of magnetization of each sample

- Mean direction of magnetization of the group

D Direction of axial dipole field at the site
}

Fig. 3. Red band from the Beacon sandstone - Direction of magnetization. 
It will be seen (Table 1 and Fig. 3 ) that the mean magnetization differs from that of the indubitably younger dolerites by only about 4 degrees, an amount closely comparable with the inherent uncertainties of the method. It seems probable that the large intrusive masses nearby have caused suffcient heating to impose a component of partial thermo-remanent magnetization aligned with the ambient field at the time of intrusion. In support of this view is the scatter of the mean directions of magnetization obtained from the three sites. Site 2 , which shows a mean direction of magnetization significantly different from that of the dolerites, was separated by no less than $\mathbf{5 0 0}$ feet of sandstone from the over- and under-lying igneous rocks. At sites 1 and 3 the thermal insulation was not quite so substantial. It must be concluded, therefore, that this magnetization is not an original one, and is significant only in that it lends support to the result obtained for the dolerite formation.

\section{Conclusions}

Uncertainties in geological age and - for the Cape Hallett lavas - of the sampling procedure, preclude any precise statements. However, some general conclusions may be drawn.

Here, as elsewhere, reversed directions of magnetization occur and may be interpreted as representative of reversals of the main magnetic field of the earth. Cenozoic rocks appear to have been magnetized in a mean field not essentially different from that of a geocentric dipole aligned with the present axis.

Older rocks are magnetized in a direction significantly different from that of the present mean magnetic field. This may be interpreted as evidence of polar wandering, implying a polar movement of some 30 degrees since the later part of the Mesozoic era. The data are perhaps too sparse to admit of a discussion of continental drift.

\section{References}

Collinson, D. W., K. M. Creer, E. Irving, and S. K. Runcorn. 1957. Palaeomagnetic measurements in Great Britain, I- The measurement of the permanent magnetization of rocks. Phil. Trans. Roy. Soc. Lond. A. 250: 73-82.

Creer, K. M., E. Irving, and S. K. Runcorn. 1957. Palaeomagnetic measurements in Great Britain, VI - Geophysical interpretation of palaeomagnetic measurements from Great Britain. Phil. Trans. Roy. Soc. Lond. A. 250:144-56.

Creer, K. M. 1958. Preliminary palaeomagnetic measurements from South America. Ann. Géophysique 14: 373-90.

Debenham, F. 1921. The sandstones, etc. of the McMurdo Sound, Terra Nova Bay, and Beardmore Glacier regions. Brit. Antarct. ("Terra Nova") Exped. 1910. Nat. Hist. Rept., Geol. 1:101-9.

Fisher, Sir R. A. 1953. Dispersion on a sphere. Proc. Roy. Soc. A. 217: 295.

Graham, J. W. 1947. The stability and significance of magnetism in sedimentary rocks. J. Geophys. Res. 54: 131.

Irving, E., and R. Green. 1957. Palaeomagnetic evidence from the Cretaceous and Cainozoic. Nature (Lond.) 179: 1064.

Runcorn, S. K. 1954. The earth's core. Trans. Am. Geophys. Union 35: 49.

Watson, G. S., and E. Irving. 1957. Statistical methods in rock magnetism. Mon. Not. Roy. Astron. Soc. Geophys. Suppl. 7:289. 